\title{
Seismic Performance Evaluation and Analysis of Major Arch Dams Considering Material and Joint Nonlinearity Effects
}

\author{
Mohammad Amin Hariri Ardebili and Hasan Mirzabozorg \\ Department of Civil Engineering, K. N. Toosi University of Technology, P.O. Box 15875-4416, Tehran, Iran \\ Correspondence should be addressed to Mohammad Amin Hariri Ardebili, amin_hariri@sina.kntu.ac.ir \\ Received 10 September 2011; Accepted 18 October 2011 \\ Academic Editor: D. N. Singh
}

Copyright (C) 2012 M. A. Hariri Ardebili and H. Mirzabozorg. This is an open access article distributed under the Creative Commons Attribution License, which permits unrestricted use, distribution, and reproduction in any medium, provided the original work is properly cited.

\begin{abstract}
Seismic failure of major concrete dams can be disastrous due to sudden release of reservoir water. At the present study, $203 \mathrm{~m}$ DEZ arch dam was selected as case study, and two types of nonlinearity were incorporated in seismic analysis of dam, joint nonlinearity and material nonlinearity. The finite element model of the dam, soil, and water was excited using multicomponent maximum design earthquake record which was extracted from seismic hazard analysis of the dam site. Also seismic performance of the dam was evaluated based on linear analysis. The extension of overstressed areas, demand-capacity ratio, and cumulative inelastic duration were used to identify the necessity of nonlinear analysis. It was found that when contraction joints between dam blocks are modeled, the direction of the principal stresses and their distribution patterns are changed meaningfully. In addition, overstress surfaces on the dam body change in comparison with the model without contraction joints.
\end{abstract}

\section{Introduction}

Generally, analyses of arch dams and preliminary study of responses are based on linear elastic (LE) model of damsoil-water coupled system. If observed responses of the dam under seismic loads and estimated damage by engineering judgment satisfy predefined criteria, so using only LE model for interpretation of results is enough. On the other hand, if severe damages, high stresses, and abnormal drifts are observed during seismic load, it is impossible to ignore the necessity for further investigations considering nonlinear behavior of concrete and/or joints. There are several approaches for modeling the stress-strain relationship of the mass concrete. In this regard, several researches have been conducted to study the dynamic behavior of concrete arch dams. Hall proposed a simple smeared crack model for modeling contraction and construction joints and diagonal cracking that is neglected in his work [1]. Espandar and Lotfi applied nonorthogonal smeared crack approach and elastoplastic models on Shaheed Rajaee arch dam in Iran [2]. Mirzabozorg et al. developed a model based on damage mechanics approach in 3D space $[3,4]$. Also, they developed a model based on smeared crack approach in $3 \mathrm{D}$ space. In their work, they analyzed 3D models including dam-reservoir interaction effects and considered nonlinear behavior of structure [5]. Calayir and Karaton analyzed gravity damreservoir system using continuum damage model of concrete [6]. Their model was a second-order tensor and includes the strain softening behavior. Akköse et al. investigated elastoplastic response of arch dams using Drucker-Prager model and found that it is a fast tool in estimation of cracks location within dam body [7]. Xiao and Lin proposed a viscoplastic model for analysis of high arch dams [8]. They used modified version of Hsieh-Ting-Chen four-parameter model for mass concrete.

On the other hand, there are many researchers that studied nonlinear behavior of joints during seismic excitation. Lau et al. introduced a joint element, which had ability to simulate opening/closing, sliding, and also behavior of shear keys [9]. By using a time domain and discrete parameter procedure for modeling dam canyons, Zhang et al. combined effects of dam-canyon interaction with contraction joint opening [10]. Ahmadi et al. introduced a nonlinear joint element with coupled tension-shear behavior for analysis of arch dam-reservoir system [11]. Xinjia et al. investigated joints openings in Xiaowan, Dagangshan, and Xiluodu dams 


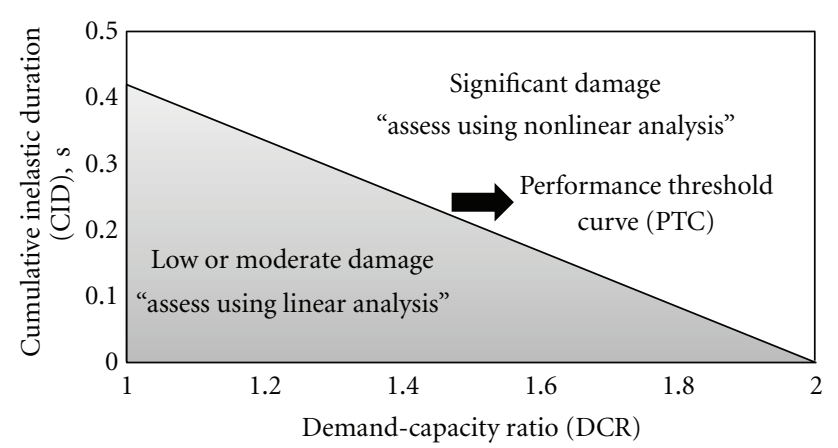

FIGURE 1: The performance curve for concrete arch dams.

[12]. In these analyses, the concrete was assumed to be linear elastic, and mass-less foundation was used for canyon rock with a few exceptions, where the infinite mass canyon and nonuniform free-field or viscous-spring boundary input models were also considered together with nonlinear joint opening. Lotfi and Epandar used discrete crack method, non-orthogonal smeared crack, and combination of them for nonlinear seismic analysis of arch dams [13]. Wang and Li studied contraction joint opening behavior of arch dams by shaking table tests [14]. Du and Tu combined explicit finite element method with transmitting boundary to study the effects of contraction joint opening on the response of Xiaowan arch dam, but only five joints were simulated [15]. Barpi and Valente investigated joint opening in a damfoundation interaction problem, and also they studied effects of water penetration into the joints [16]. Yu et al. studied differences of discrete and continuum models in modeling concrete fracture [17]. In addition, other researchers such as $\mathrm{Hu}$ et al. [18], Lotfi and Espandar [19] studied effects of contraction joints in seismic analysis of arch dams.

In the present study, material and joint nonlinearity effects on seismic response of major arch dams are investigated. For this purpose, three finite element models were generated as follows: dam body with linear elastic material; dam body with linear material including contraction and perimetral joints; at last, dam body with nonlinear mass concrete. The reservoir water level was taken to be $96.9 \%$ of total height of the dam (corresponding to the normal water level of the reservoir), and the thermal distribution within the dam body corresponding to the summer condition extracted from the conducted transient thermal analysis including solar radiation effects was applied before exciting the system with appropriate three-component earthquake records. Moreover, the necessity of nonlinear analysis was evaluated using recent introduced criteria like as demandcapacity ratio (DCR), cumulative inelastic duration (CID) extension of overstressed areas on upstream (US), and downstream (DS) faces of the dam body.

\section{Detecting Necessity of Conducting Nonlinear Analysis}

Performance evaluation is formulated based on magnitudes of DCRs, cumulative duration of stress excursions beyond the tensile strength of concrete, and extension of overstressed regions on US and DS faces [20]. The demand-capacity ratio for plain concrete is defined as the ratio of computed tensile stress to tensile strength of the concrete. In the case of arch dams, where high stresses are usually oriented in the arch and cantilever directions, DCR is evaluated using arch or cantilever stress demands. The tensile strength or capacity of the plain concrete used in computation of DCR is obtained from the uniaxial splitting tension tests. The maximum permitted DCR for linear analysis of dams is 2.0. This corresponds to a stress that demands twice the tensile strength of the concrete. For assessing the probable level of damage, the cumulative inelastic duration is utilized in conjunction with DCR. CID refers to the total duration of stress excursions above the tensile strength of the concrete, which as a measure of energy is a better indicator of the damage than the number of stress cycles. Arch dams that resist loads through both the arch and cantilever actions can sustain higher level of nonlinear deformation (or longer CID) than gravity dams that rely on cantilever mechanism alone to resist loads. The performance curve for arch dams is shown in Figure 1 [21].

In addition to the foregoing performance criteria, the proposed damage criteria require to be limited in small regions, so that the evaluation on the basis of linear analysis is still valid. If the extension of damage or nonlinear response is limited to $20 \%$ of total areas of upstream or downstream faces, the linear analysis is still valid.

\section{Nonlinear Behavior of Concrete Dams}

3.1. Contraction and Perimetral Joints. At the present study, for modeling joints, a special contact element is used which is able to model contact between two adjacent nodes in $3 \mathrm{D}$ domain. This contact element supports only compression in normal direction and also shears in the tangential direction. Figure 2 shows the flowchart used for calculating force in contact elements [22], in which, $\vec{V}$ is a vector representing contact state in which $V_{n}$ indicates the state in the normal direction to the plane of the joint, and $V_{r}$ and $V_{s}$ indicate the state of the considered contact element in tangential directions. Moreover, Figure 3 shows forcedeflection relations for both normal and tangential status. In this flowchart, $F_{n}, F_{r}$, and $F_{s}$ are local components of force vector; $F_{g}$ is sliding force in the joint; $F_{t}$ is shear force resultant in the joint; $K_{n}$ and $K_{t}$ are normal and tangential stiffness of the joint, and $\mathrm{a}$ is the angle between the two components of in-plane shear.

As shown, contact element cannot endure any tensile force or stress, but when it is in compression, it can suffer compression forces according to its normal stiffness coefficient and shear forces according to its tangential stiffness coefficient. When shear force resultant in the joint exceeds the joint sliding resisting force, the two nodes of the element begin sliding with respect of each other. Joint sliding force is calculated using coulomb friction law. In Figure 2, $c$ is cohesion factor, and $\mu$ is friction coefficient. 


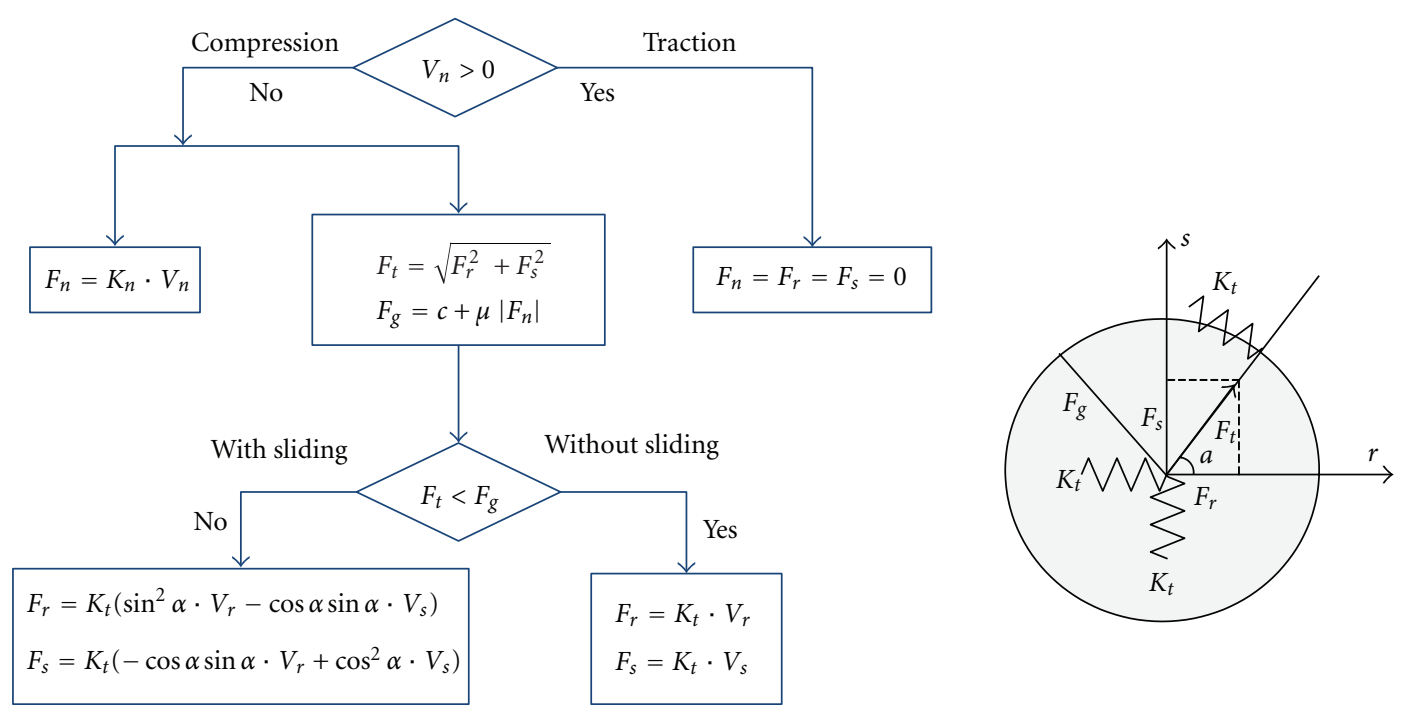

FIGURE 2: Flowchart for calculating force in joints.

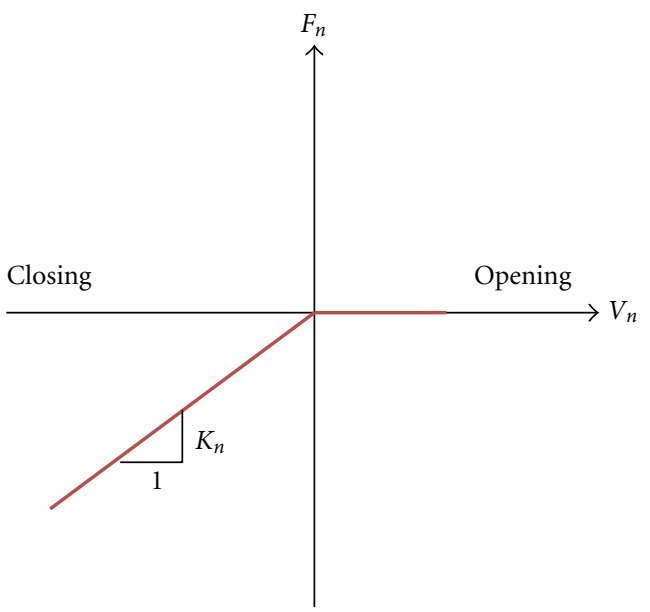

(a)

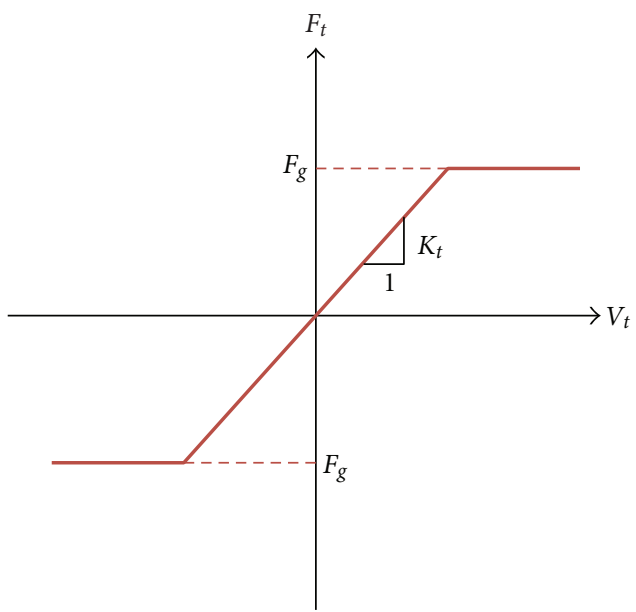

(b)

Figure 3: Force-deflection relations for joint (a) normal opening, (b) tangential movement.

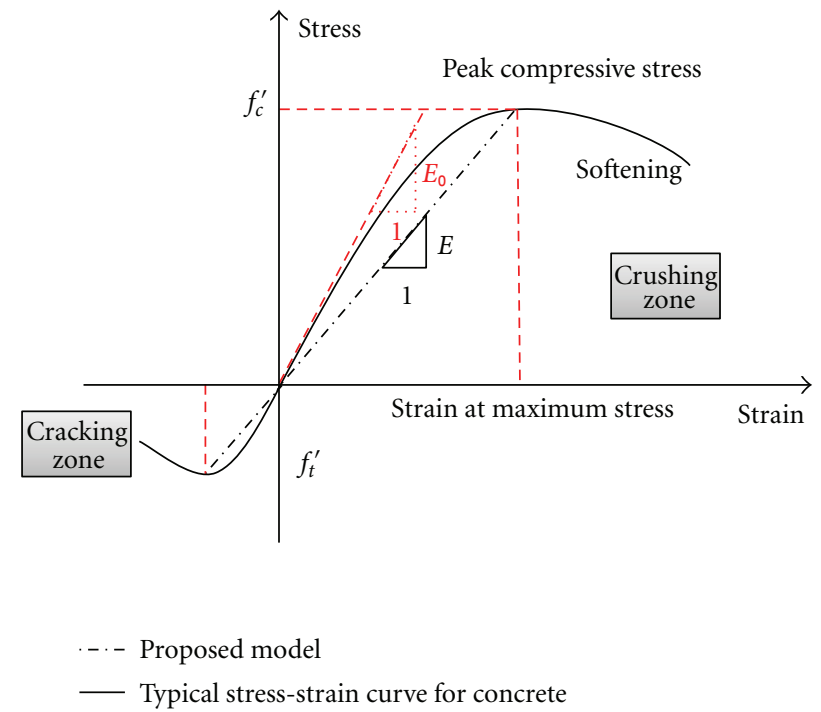

FIgURE 4: Typical and proposed uniaxial compressive and tensile stress-strain curve for mass concrete.

3.2. Material Nonlinearity. Continuum crack propagation model is utilized to simulate nonlinear behavior of mass concrete. In this model, the fracture is idealized to propagate as a blunt front smeared over an entire element or a certain band width of the element. After initiation of the fracture process, determined by a suitable constitutive model, the precrack material stress-strain relation is replaced by an orthotropic relation with material reference axis system aligned with the fracture direction. The tension stiffness across the crack plane is either eliminated suddenly or a gradual stress-release criterion is applied. Thus, only the constitutive relation is updated with propagation of cracks, and the finite element mesh is kept unchanged. The advantage of the models lies in its simplicity and cost effectiveness, although the physical 


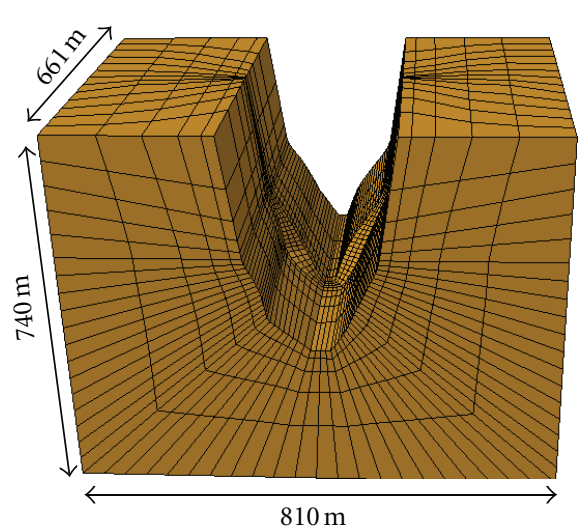

(a)

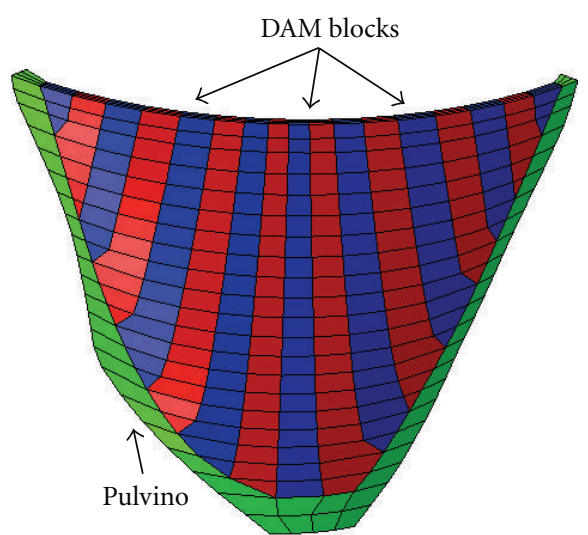

(b)

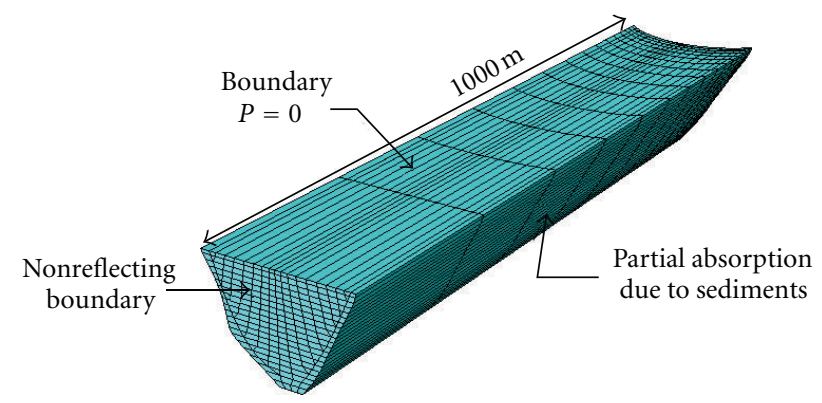

(c)

Figure 5: Finite element model of dam, soil, and water.

nature of crack representation is questionable [23]. The behavior of concrete elements is assumed linear elastic until it reaches ultimate strength (Figure 4), and at this stage the elasticity modulus of concrete is considered as the average $E$ instead of the linear actual $E_{0}$.

Cracking occurs when the principal tensile stress in any direction lies outside the failure surface. After cracking, the elastic modulus of the concrete element is set to a reduced magnitude in the direction parallel to the principal tensile stress direction. In the utilized model, cracking is permitted in three orthogonal directions at each integration point. When cracking occurs at an integration point, the stressstrain relation is modified by defining a weak plane normal to the crack direction. In addition, the presence of crack at an integration point and in special direction represents through modification of stiffens matrix by exerting shear transfer coefficient in cracked plane.

\section{Finite Element Model of Dam-Water-Soil System}

DEZ is $203 \mathrm{~m}$ high double curvature arch dam with a perimetral joint separating the dam body from a concrete saddle structure called Pulvino. The dam is located in a narrow gorge at the DEZ River in Khuzestan province in Iran, about $150 \mathrm{~km}$ upstream of provincial capital, Ahwaz. The finite element model prepared for dam, soil, and water is presented in Figure 5. The model consists of 792 eight-node solid elements for modeling concrete dam and saddle and 3770 eight-node solid elements for modeling soil. The eight-node solid elements have three degrees of freedom at each node that are translated in the $x, y$, and $z$ directions. In addition, water is modeled using 3660 eight-node fluid elements. Utilized fluid elements have three translation DOFs and one pressure DOF in each node. It should be noted that translation DOFs are active only at nodes that are on the interface with solid elements. Also, 956 contact elements are used for modeling contraction and perimetral joints. Normal and tangential stiffness for contact elements are taken as $240 \mathrm{GPa} / \mathrm{m}$ and $24 \mathrm{GPa} / \mathrm{m}$ based on sensitive analyses conducted by the authors. These stiffness coefficients lead to reasonable opening/closing and sliding in contraction joints in comparison with results obtained from joint meters installed in central block of the dam.

Furthermore, material properties for mass concrete and soil are described in Table 1 [24]. Reservoir water density is $1000 \mathrm{~kg} / \mathrm{m}^{3}$, sound velocity in water is taken as $1440 \mathrm{~m} / \mathrm{s}$, and wave reflection coefficient for reservoir around boundary is assumed 0.8 , conservatively. The $\beta$-Newmark method is utilized to solve the coupled nonlinear problem of dam-soilwater model.

\section{Loading History}

Applied loads on the simulated system and their sequences are (1) the dam body dead load; (2) hydrostatic pressure 
TABLE 1: Material properties of mass concrete and foundation rock.

\begin{tabular}{|c|c|c|c|c|c|c|c|c|c|c|}
\hline \multirow[b]{2}{*}{$\begin{array}{l}\text { Material } \\
\text { properties }\end{array}$} & \multirow[b]{2}{*}{$\begin{array}{l}\text { Isotropic } \\
\text { elasticity }\end{array}$} & \multirow[b]{2}{*}{$\begin{array}{l}\text { Poisson's } \\
\text { ratio }\end{array}$} & \multicolumn{3}{|c|}{ Mass concrete } & \multirow[b]{2}{*}{$\begin{array}{l}\text { Uniaxial } \\
\text { tensile } \\
\text { strength }\end{array}$} & \multirow[b]{2}{*}{$\begin{array}{l}\text { Compressive } \\
\text { strength }\end{array}$} & \multicolumn{3}{|c|}{ Soil } \\
\hline & & & Density & $\begin{array}{l}\text { Thermal } \\
\text { expansion } \\
\text { coefficient }\end{array}$ & $\begin{array}{c}\text { Grouting } \\
\text { temperature }\end{array}$ & & & $\begin{array}{l}\text { Isotropic } \\
\text { elasticity } \\
\text { (saturated) }\end{array}$ & $\begin{array}{c}\text { Isotropic } \\
\text { elasticity } \\
\text { (unsaturated) }\end{array}$ & $\begin{array}{l}\text { Poisson's } \\
\text { ratio }\end{array}$ \\
\hline $\begin{array}{l}\text { Static } \\
\text { properties }\end{array}$ & $40 \mathrm{GPa}$ & 0.2 & $2400 \mathrm{~kg} / \mathrm{m}^{3}$ & $\begin{array}{c}6 E-006 \\
1 /{ }^{\circ} \mathrm{C}\end{array}$ & $23^{\circ} \mathrm{C}$ & $35 \mathrm{MPa}$ & $3.4 \mathrm{MPa}$ & $13 \mathrm{GPa}$ & $15 \mathrm{GPa}$ & 0.25 \\
\hline $\begin{array}{l}\text { Dynamic } \\
\text { properties }\end{array}$ & $46 \mathrm{GPa}$ & 0.14 & $2400 \mathrm{~kg} / \mathrm{m}^{3}$ & $\begin{array}{c}6 E-006 \\
1 /{ }^{\circ} \mathrm{C} \\
\end{array}$ & $23^{\circ} \mathrm{C}$ & $36.5 \mathrm{MPa}$ & $5.1 \mathrm{MPa}$ & $13 \mathrm{GPa}$ & $15 \mathrm{GPa}$ & 0.25 \\
\hline
\end{tabular}

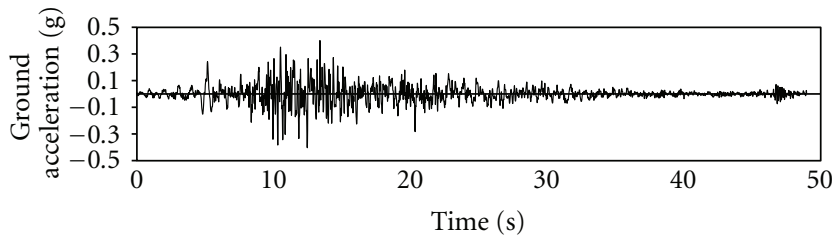

- Component L

(a) Scaled accelerogram for Tabas earthquake at tabas station (Component L, MCL)

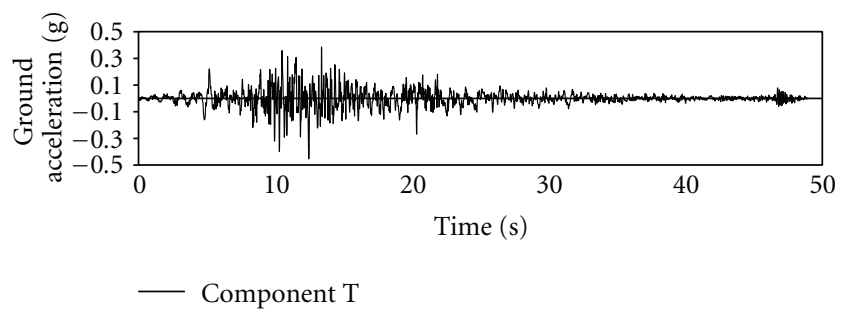

(b) Scaled accelerogram for Tabas earthquake at tabas station (Component T, MCL)

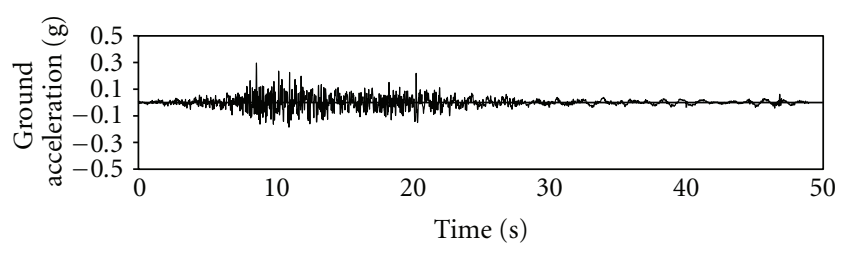

- Component V

(c) Scaled accelerogram for Tabas earthquake at tabas station (Component V, MCL)

Figure 6: TABAS ground motion components recorded at TABAS station (L: stream direction, $\mathrm{T}$ : cross section direction, and V: vertical direction).

considering gradual impounding; (3) thermal load corresponding to summer condition; (4) earthquake load. It is worth noting that in all the conducted analyses, construction stages are modeled before impounding of the reservoir in accordance with the existing construction reports of the project [24].

For dynamic loading, the system is excited at the foundation boundaries using TABAS earthquake records scale based on design spectrum of the dam site corresponding to maximum design level. It is notable that all three components are applied to system simultaneously. Total time duration of the record is $48.9 \mathrm{~s}$ (Figure 6). For specifying

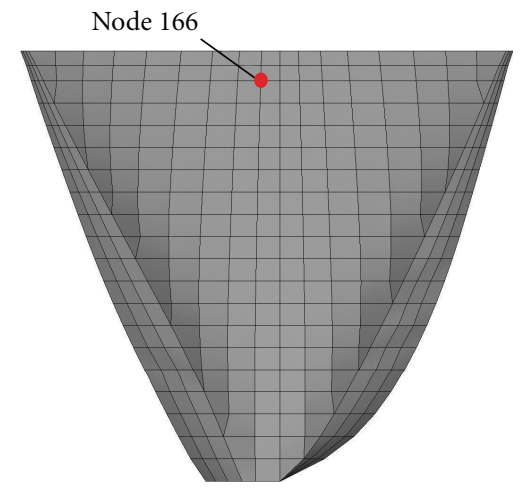

(a)

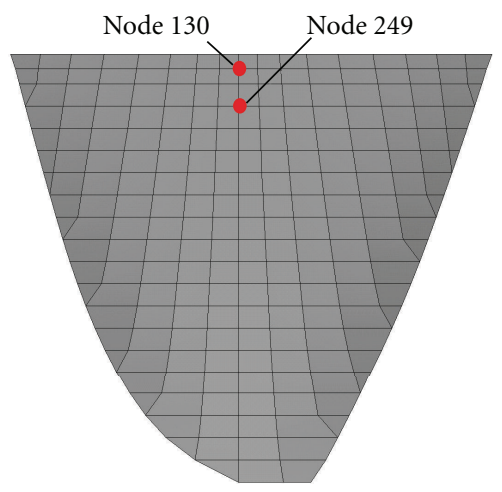

(b)

FIGURE 7: Location of critical nodes in US and DS faces of dam body.

significant duration of excitation, arias intensity on Husid diagram is used, and then time interval between $5 \%$ and 95\% of arias intensity based on Trifunac and Brady theory is selected [25]. With this method, significant time duration is obtained to be $21.40 \mathrm{~s}$ (time between $4.1 \mathrm{~s}$ and $25.5 \mathrm{~s}$ ). Based on analyses conducted by the authors, structural damping should be considered as $5 \%-10 \%$. In the present paper, structural damping is taken $7 \%$ of critical damping and Rayleigh damping method is utilized to determine the mass and stiffness proportional damping coefficients.

\section{Numerical Results and Discussion}

6.1. Discussion on Necessity of Nonlinear Analysis. According to criteria introduced in Section 2, one node on the DS face 


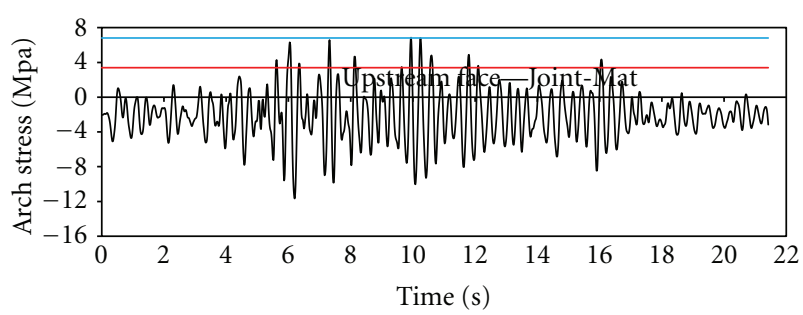

Node number 130 on US face

(a)

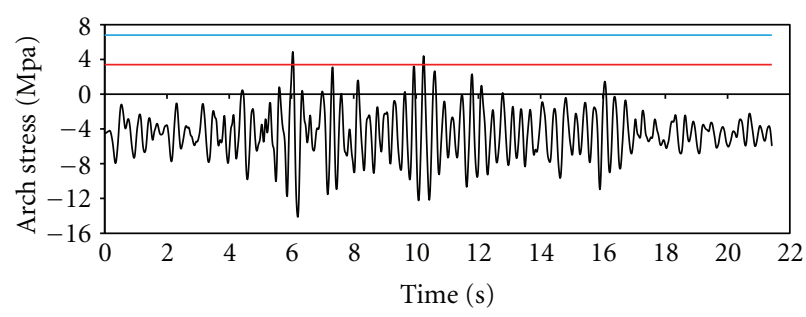

Node number 249 on US face

(b)

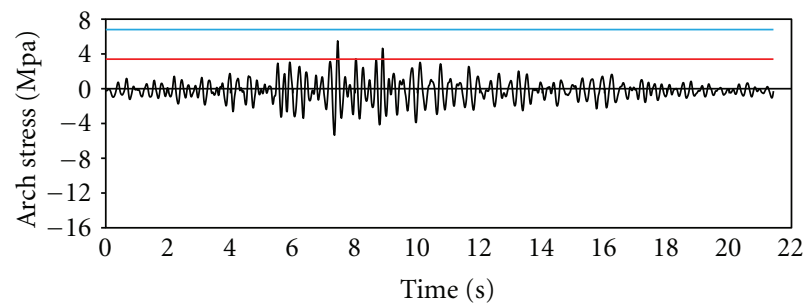

Node number 166 on DS face

(c)

FIgURE 8: Arch stresses at critical nodes, and the limits of DCR $=1$ and DCR $=2$.

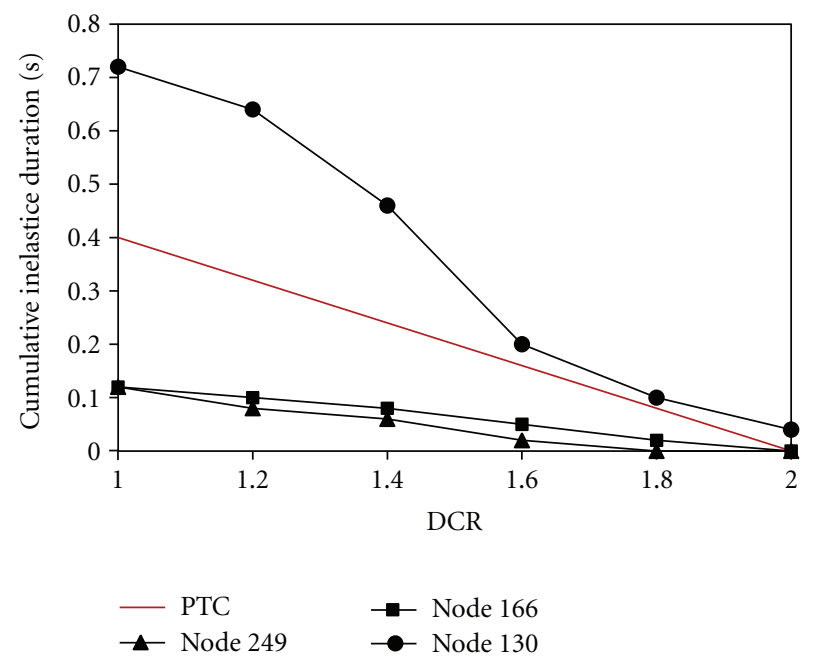

FIGURE 9: The cumulative inelastic duration for three critical nodes.

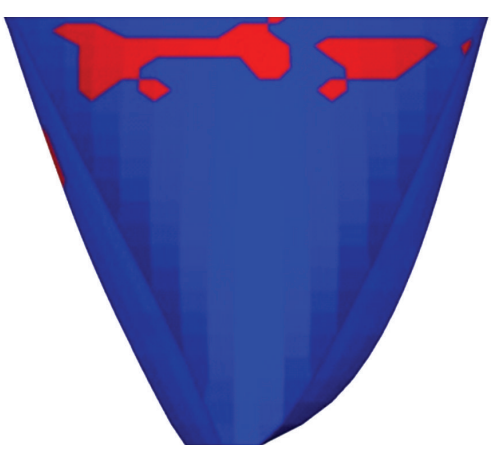

DS (about $10.3 \%$ overstressed)

(a)

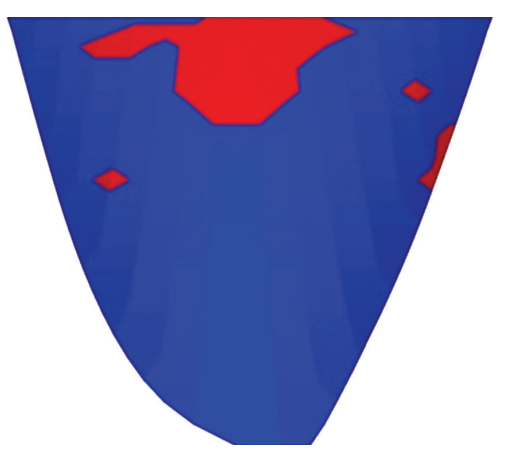

US (about $14.8 \%$ overstresses)

(b)

FIgURE 10: Percentage of overstress areas within dam body.

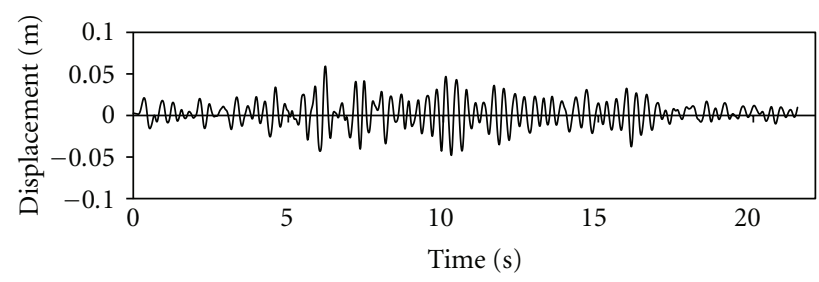

— Center

(a)

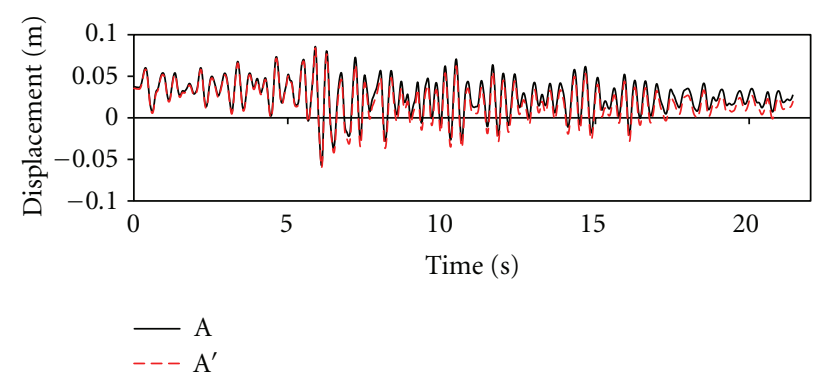

(b)

FIGURe 11: Time-history of displacement at crest node(s) of crown cantilever in stream direction, (a) mat-non, (b) joint-non. 


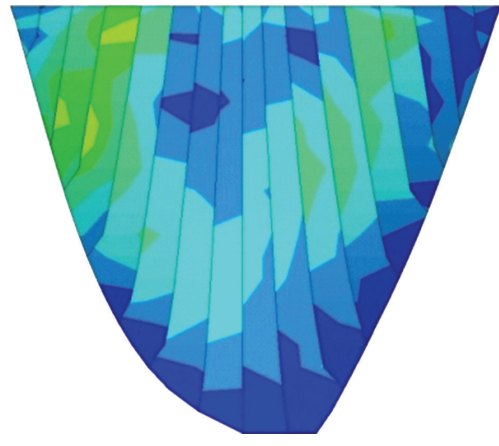

Upstream face-Joint-Non

(a)

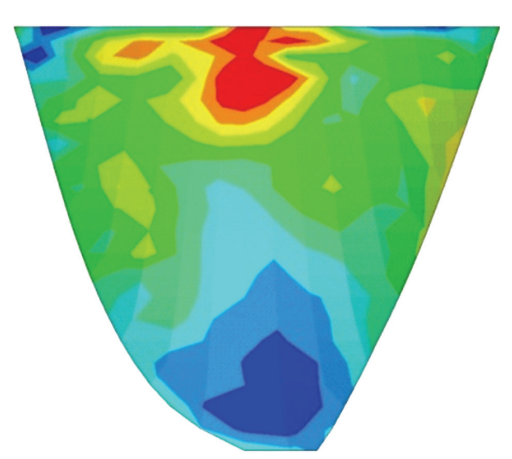

Upstream face-Mat-Non

(c)

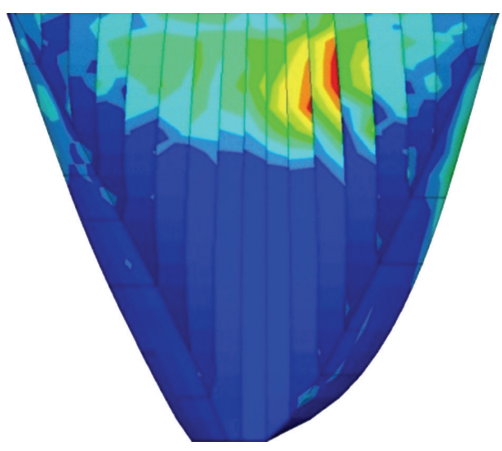

Downstream face—Joint-Non

(b)

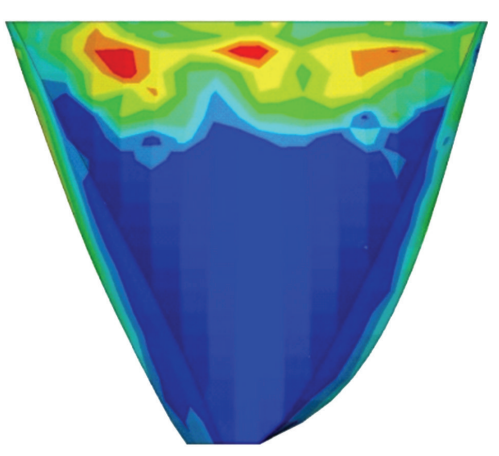

Downstream face-Mat-Non

(d)
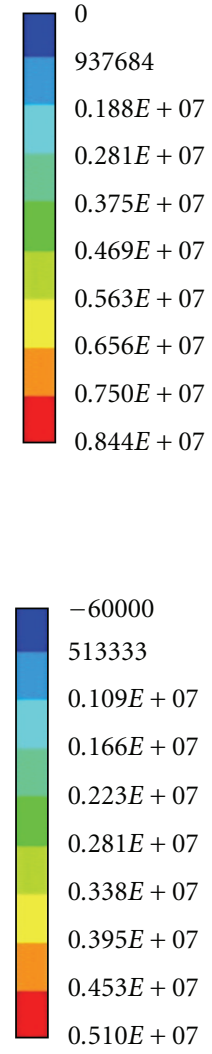

$0.510 E+07$

FIGURE 12: Nonconcurrent envelope of maximum principal stress within dam body.

and two nodes on the US face of the dam body which are most critical are selected and principal stresses at these nodes are extracted. Figure 7 shows the location of mentioned nodes on US and DS faces, and Figure 8 shows the time history of stresses at the considered nodes.

As shown in the recent time histories, the value of stresses exceeds DCR $=1$ at node No. 130 frequently. In addition, the maximum tensile stress at this node exceeds the limit of DCR $=2$. On the other hand, at nodes 249 and 166, there are stresses which are beyond the limit of DCR $=1$; however, there is not any stress larger than two times of the tensile strength. CID at the considered nodes is shown in Figure 9. As can be seen, CID for node 130 is always above the performance threshold curve (PTC) which is interface between linear and nonlinear regions and proves the fact that the dam must be studied using nonlinear numerical models for obtaining reliable results. In addition, as can be seen the critical node on DS face never exceeds PTC, and it means that DS face always is in safe margin.

The third criterion for considering the necessity of nonlinear analysis is extension of overstressed areas on US and DS faces of the dam body. Figure 10 shows the areas corresponding to DCR greater than unity on US and DS faces. Based on the processed results, about $14.8 \%$ of the US face and $10.3 \%$ of the DS face are overstressed which are less than $20 \%$, the criterion specified in [21]. However, due to exceeding stresses at some locations from the two times of the concrete tensile strength, utilizing nonlinear analyses for evaluating the structural safety of DEZ is necessary.

6.2. Nonlinear Analyses. In the current section, the results from the two conducted nonlinear analyses which include joint nonlinearity (Joint-Non) and material nonlinearity (Mat-Non) are discussed. Figure 11 shows time history of the crest displacement in stream direction at crown cantilever extracted from models based on two mentioned models. It should be noted that for model with joint nonlinearity, there are two nodes at each location which are on the left and right blocks. For example, nodes $A$ and $A^{\prime}$ are both on the crown cantilever at the same location; the first one is on the left block, and the second node is on the right block. Also Table 2 represents the extreme values extracted from crest results.

Based on the presented results, stage construction can affect extensively the crest displacement. As can be seen, static displacement extracted from joint-non on crown cantilever is $36.42 \mathrm{~mm}$ (average value of $A$ and $A^{\prime}$ ), and for MatNon this value decreases to $2.64 \mathrm{~mm}$. The main reason of increasing displacements in joint-non is due to modeling vertical contraction joints between dam blocks and sliding of the adjacent blocks due to stage construction. Moreover, it can be found that there are many differences between 


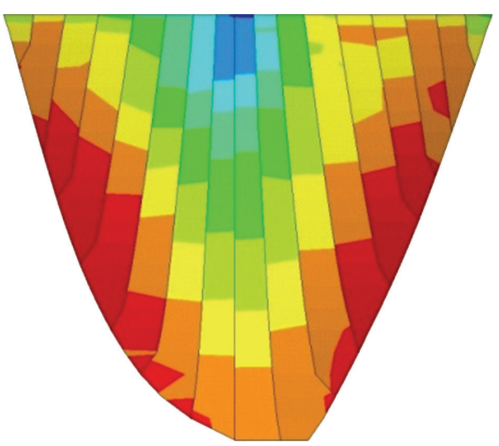

Upstream face-Joint-Non

(a)

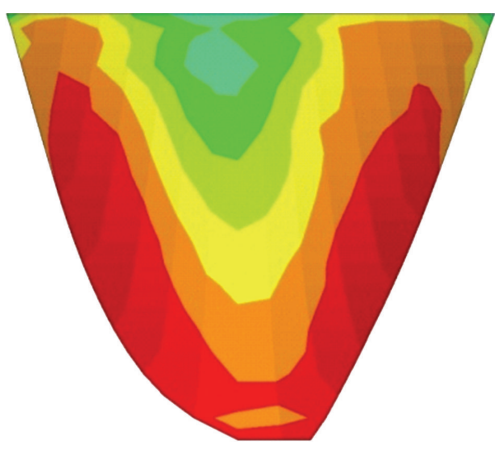

Upstream face-Mat-Non

(c)

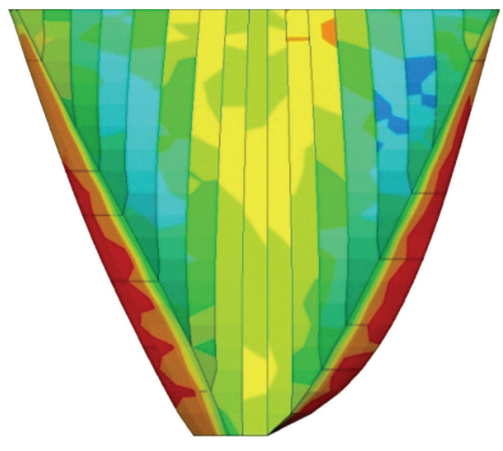

Downstream face-Joint-Non

(b)

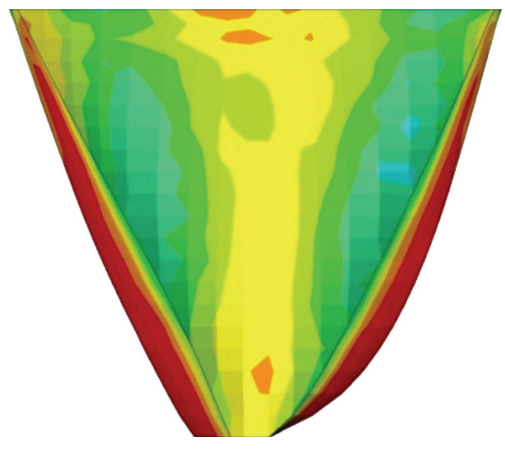

Downstream face-Mat-Non

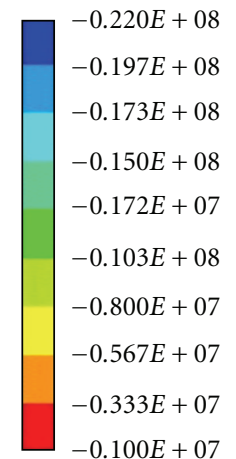

$-0.100 E+07$

FIGURE 13: Nonconcurrent envelope of minimum principal stress within dam body.

TABLE 2: Crest displacement in US/DS direction.

\begin{tabular}{|c|c|c|c|c|c|c|c|c|c|}
\hline \multirow[b]{3}{*}{ Ctotis } & \multicolumn{3}{|c|}{ Mat-non model } & \multicolumn{6}{|c|}{ Joint-non model } \\
\hline & \multirow{2}{*}{$\begin{array}{c}\begin{array}{c}\text { Centre node } \\
(\mathrm{mm})\end{array} \\
2.64\end{array}$} & \multirow{2}{*}{$\begin{array}{c}\begin{array}{c}\text { Left quarter node } \\
(\mathrm{mm})\end{array} \\
-5.86\end{array}$} & \multirow{2}{*}{$\begin{array}{c}\begin{array}{l}\text { Right quarter node } \\
(\mathrm{mm})\end{array} \\
-3.68\end{array}$} & \multicolumn{2}{|c|}{ Centre nodes $(\mathrm{mm})$} & \multicolumn{2}{|c|}{ Left quarter nodes $(\mathrm{mm})$} & \multicolumn{2}{|c|}{ Right quarter nodes $(\mathrm{mm})$} \\
\hline & & & & 37.36 & 35.47 & -16.03 & -23.42 & -1.61 & +9.79 \\
\hline \multicolumn{10}{|c|}{ Dynamic } \\
\hline US & -48.00 & -29.52 & -26.11 & -57.46 & -59.60 & -77.92 & -54.83 & -25.2 & -22.4 \\
\hline DS & 59.13 & 27.38 & 18.13 & 85.81 & 84.13 & 7.48 & 31.18 & 25.30 & 29.31 \\
\hline
\end{tabular}

joint-non and mat-non at quarter nodes which makes these two models incomparable along the crest.

Table 3 shows the extreme values of maximum and minimum principal stresses along the crest at the specified points extracted from material and joint nonlinearity models. It is found that in this region, minimum principal stress in joint-non model has greater absolute value than mat-non model. Also in crest of crown cantilever mat-non model reaches to ultimate tensile strength and splits. Modeling contraction joints reduce maximum principal stresses in joint-non model, and it reaches to only $2 \mathrm{MPa}$ at center of the crest.

Figures 12 and 13 represent nonconcurrent envelope of maximum and minimum principal stresses, respectively, for both joint-non and mat-non. Based on these envelopes, general pattern of minimum principal stress distribution almost the same for the two considered models. However, there is significant difference in distribution pattern of maximum principal stresses. It is worth noting that tensile stress distribution is an important issue in interpreting results of dynamic analyses of arch dams and therefore, can lead to decision making in design stage for new dams or in rehabilitation studies for old dams. Finally, cracked elements based on mat-non model on US and DS faces are depicted in Figure 14. In present model, cracking in element is modeled by cracking of integration points. Considering that eightnode solid elements with eight integration points were used in this paper for simulation of dam body, if at least five integration points crack in certain element, the considered element is introduced as cracked element. 
TABLE 3: Maximum (S1) and minimum (S3) principal stresses in crest nodes.

\begin{tabular}{|c|c|c|c|c|c|c|c|c|c|}
\hline \multirow{2}{*}{$\begin{array}{l}\text { Principal } \\
\text { Stresses }\end{array}$} & \multicolumn{3}{|c|}{ Mat-non model } & \multicolumn{6}{|c|}{ Joint-non model } \\
\hline & $\begin{array}{c}\text { Centre node } \\
(\mathrm{MPa})\end{array}$ & $\begin{array}{l}\text { Left quarter } \\
\text { node }(\mathrm{MPa})\end{array}$ & $\begin{array}{l}\text { Right quarter } \\
\text { node }(\mathrm{MPa})\end{array}$ & Centre $n$ & des $(\mathrm{MPa})$ & Left quar & r nodes $(\mathrm{MPa})$ & Right qu & er nodes $(\mathrm{MPa})$ \\
\hline S1 & 5.10 & 1.84 & 1.71 & 2.00 & 1.41 & 2.32 & 4.21 & 3.04 & 1.17 \\
\hline S3 & -13.7 & -11.1 & -7.8 & -20.1 & -20.2 & -13.1 & -11.6 & -7.1 & -8.6 \\
\hline
\end{tabular}

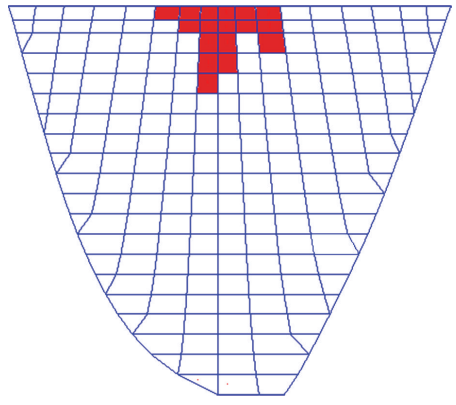

(a)

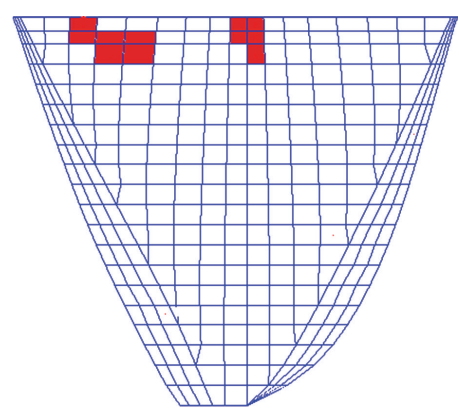

(b)

FIGURE 14: Cracked elements in US and DS face of dam body based on mat-non model.

\section{Conclusion}

In the present paper, the last published criteria for evaluating the structural performance of concrete arch dams were utilized, and the significance of modeling joint nonlinearity and/or material nonlinearity was considered. DEZ dam which is a high arch dam in Iran was chosen as the case study. At the first stage, linear elastic model of the dam body, foundation medium, and the water was prepared and seismic performance of the dam in linear domain and necessity of conducting nonlinear analyses were investigated based on DCR, CID, and extension of overstressed areas. Based on linear analyses results, although percentage of overstressed areas on both US and DS faces of the dam are below the $20 \%$, exceeding performance curve of most critical point from PTC and also existence of at least one point with DCR $>2.0$ show that nonlinear transient analysis is required for accurate study of the dam behavior during earthquake. Consequently, two nonlinear models based on joint nonlinearity and material nonlinearity approaches were prepared. In the first model, all the contraction joints and also perimetral joint were modeled using node-to-node contact element with ability of opening/sliding, and in the second one, just material nonlinearity of mass concrete with ability of cracking/crushing was considered. It was found that joint-non can affect significantly on crest displacement. Based on the results, sliding about $4 \mathrm{~mm}$ and opening about $5.5 \mathrm{~mm}$ are expected in upper parts of upstream face in vicinity of crest. In addition, the pattern of tensile stress distribution on US and DS faces cannot be obtained utilizing the model with material nonlinearity without modeling vertical joints. However, the general patterns of compressive stress distribution for the two nonlinear models are approximately comparable. Based on the obtained results, it can be concluded that modeling joints in concrete arch dams are necessary for evaluating structural performance and modeling material nonlinearity without vertical joints is not enough for this purpose.

\section{References}

[1] J. F. Hall, "Efficient non-linear seismic analysis of arch dams," Earthquake Engineering and Structural Dynamics, vol. 27, no. 12, pp. 1425-1444, 1998.

[2] R. Espandar and V. Lotfi, "Comparison of non-orthogonal smeared crack and plasticity models for dynamic analysis of concrete arch dams," Computers and Structures, vol. 81, no. 14, pp. 1461-1474, 2003.

[3] M. Ghaemian, A. R. Khaloo, H. Mirzabozorg et al., "Staggered solution scheme for three-dimensional analysis of damreservoir interaction," The Journal of Dam Engineering, vol. 14, pp. 1-33, 2003.

[4] H. Mirzabozorg, M. Ghaemian, M. R. Kianoush et al., "Damage mechanics approach in seismic analysis of concrete gravity dams including dam-reservoir interaction," European Earthquake Engineering, vol. 18, pp. 17-24, 2004.

[5] H. Mirzabozorg and M. Ghaemian, "Non-linear behavior of mass concrete in three-dimensional problems using a smeared crack approach," Earthquake Engineering and Structural Dynamics, vol. 34, no. 3, pp. 247-269, 2005.

[6] Y. Calayir and M. Karaton, "A continuum damage concrete model for earthquake analysis of concrete gravity damreservoir systems," Soil Dynamics and Earthquake Engineering, vol. 25, no. 11, pp. 857-869, 2005.

[7] M. Akköse, S. Adanur, A. Bayraktar, and A. A. Dumanoğlu, "Elasto-plastic earthquake response of arch dams including fluid-structure interaction by the Lagrangian approach," Applied Mathematical Modelling, vol. 32, no. 11, pp. 23962412, 2008.

[8] S. Y. Xiao and G. Lin, "Viscoplastic seismic response of arch dam under high hydrostatic pressure," in Proceedings of the 14th World Conference on Earthquake Engineering, Beijing, China, 2008.

[9] D. T. Lau, B. Noruziaan, and A. G. Razaqpur, "Modelling of contraction joint and shear sliding effects on earthquake 
response of arch dams," Earthquake Engineering and Structural Dynamics, vol. 27, no. 10, pp. 1013-1029, 1998.

[10] C. Zhang, Y. Xu, G. Wang, and F. Jin, "Non-linear seismic response of arch dams with contraction joint opening and joint reinforcements," Earthquake Engineering and Structural Dynamics, vol. 29, no. 10, pp. 1547-1566, 2000.

[11] M. T. Ahmadi, M. Izadinia, and H. Bachmann, "Discrete crack joint model for nonlinear dynamic analysis of concrete arch dam," Computers and Structures, vol. 79, no. 4, pp. 403-420, 2001.

[12] L. Xinjia, X. Yanjie, W. Guanglun, and Z. Chuhan, "Seismic response of arch dams considering infinite radiation damping and joint opening effects," Earthquake Engineering and Engineering Vibration, vol. 1, no. 1, pp. 65-73, 2002.

[13] V. Lotfi and R. Espandar, "Seismic analysis of concrete arch dams by combined discrete crack and non-orthogonal smeared crack technique," Engineering Structures, vol. 26, no. 1, pp. 27-37, 2004.

[14] H. Wang and D. Li, "Experimental study of seismic overloading of large arch dam," Earthquake Engineering and Structural Dynamics, vol. 35, no. 2, pp. 199-216, 2006.

[15] X. Du and J. Tu, "Nonlinear seismic response analysis of arch dam-foundation systems- part II opening and closing contact joints," Bulletin of Earthquake Engineering, vol. 5, no. 1, pp. 121-133, 2007.

[16] F. Barpi and S. Valente, "Modeling water penetration at damfoundation joint," Engineering Fracture Mechanics, vol. 75, no. 3-4, pp. 629-642, 2008.

[17] R. C. Yu, G. Ruiz, and E. W. V. Chaves, "A comparative study between discrete and continuum models to simulate concrete fracture," Engineering Fracture Mechanics, vol. 75, no. 1, pp. 117-127, 2008.

[18] Z. Q. Hu, D. Zhang, and G. Lin, "Effects of joint-movement on the earthquake response of arch dams," in Proceedings of the 14th World Conference on Earthquake Engineering, Beijing, China, 2008.

[19] V. Lotfi and R. Espandar, "An investigation of joints behavior in seismic response of arch dams," Electronic Journal of Structural Engineering, vol. 2, pp. 17-31, 2002.

[20] Y. Ghanaat, "Seismic performance and damage criteria for concrete dams," in Proceedings of the 3rd US-Japan Workshop on Advanced Research on Earthquake Engineering for Dams, San Diego, Calif, USA, 2002.

[21] EM 1110-2-6053, Earthquake Design and Evaluation of Concrete Hydraulic Structures, US Army Corps of Engineering, Washington, DC, USA, 2007.

[22] M. Azmi and P. Paultre, "Three-dimensional analysis of concrete dams including contraction joint non-linearity," Engineering Structures, vol. 24, no. 6, pp. 757-771, 2002.

[23] R. M. Gunn, "Non-linear design and safety analysis of arch dams using damage mechanics. Part 1: formulation," International Journal on Hydropower and Dams, vol. 8, no. 2, pp. 67-74, 2001.

[24] M.G. Consulting Engineering and Electrowatt Engineering Services, A Re-Analysis of the DEZ Arch Dam in Iran, Tehran, Iran, 2004.

[25] M. D. Trifunac and A. G. Brady, "A study on the duration of strong earthquake ground motion," Bulletin of the Seismological Society of America, vol. 65, pp. 581-626, 1975. 

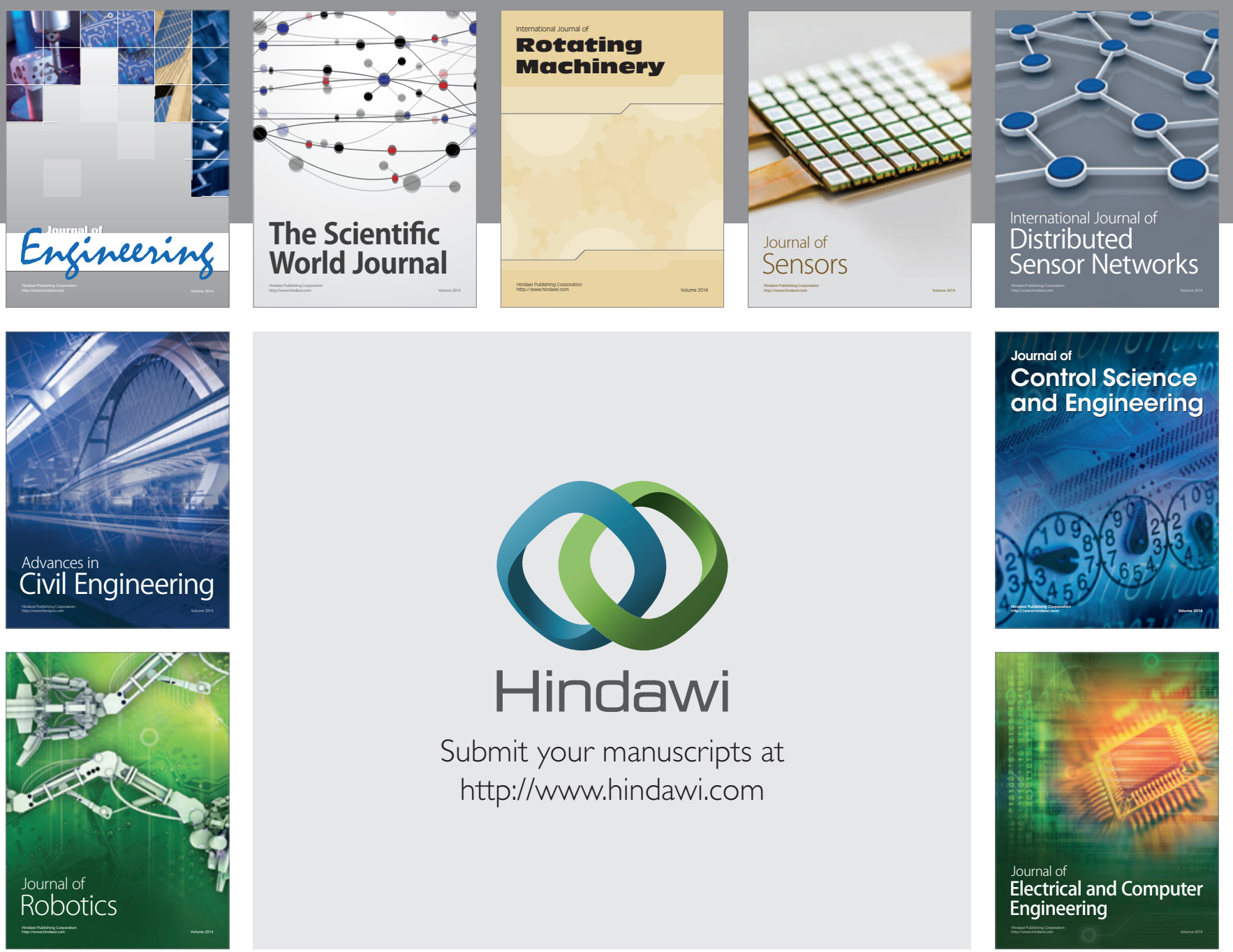

Submit your manuscripts at

http://www.hindawi.com
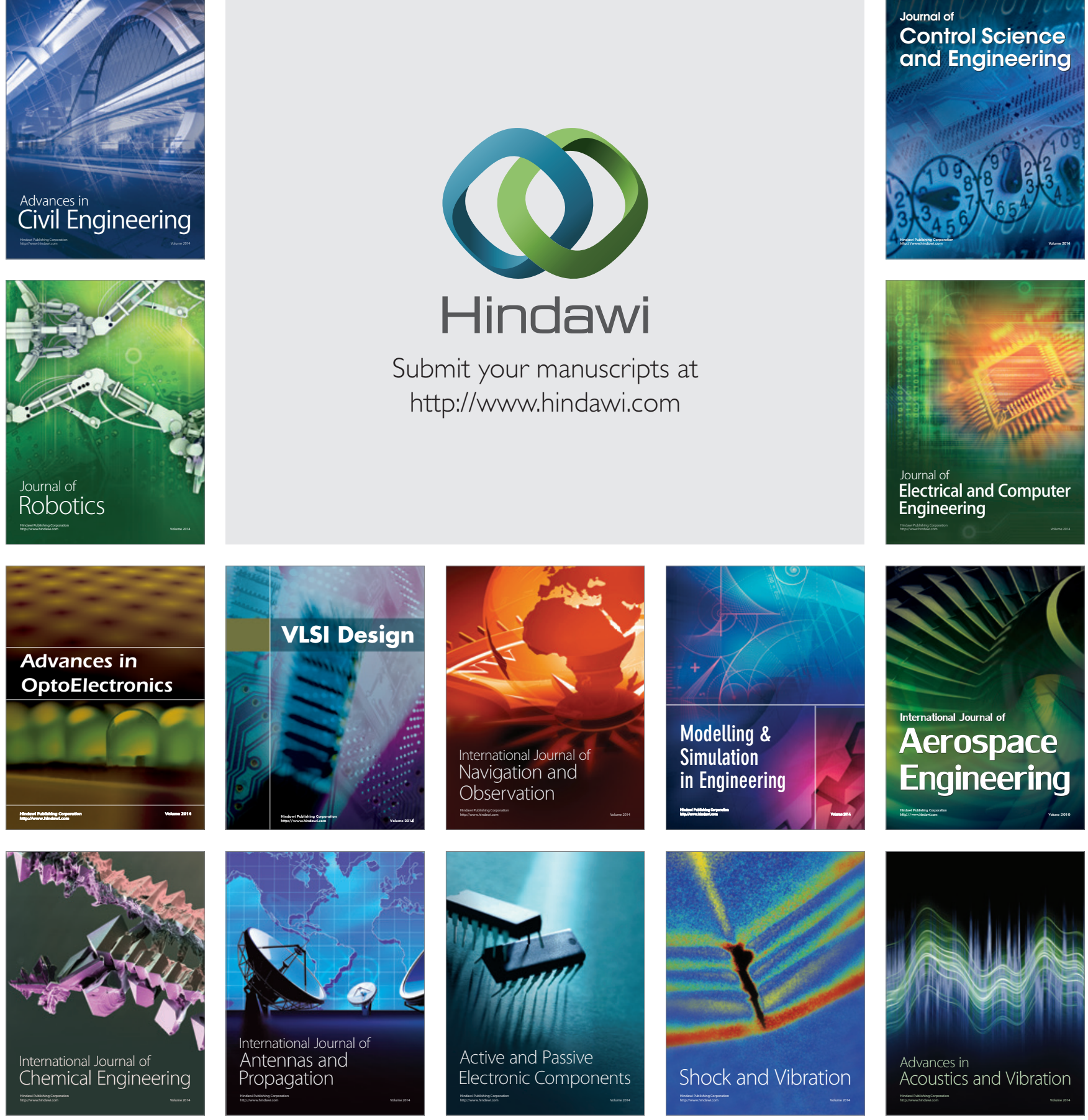